\title{
Simulation of ventilation and fire in the underground facilities
}

\author{
L.H. Cheng ${ }^{\mathrm{a}}$, T.H. Ueng ${ }^{\mathrm{b}}$, C.W. Liu ${ }^{\mathrm{c}, *}$ \\ ${ }^{a}$ Hydraulic Technical Laboratory, National Taiwan University, Taipei 10617, Taiwan, ROC \\ ${ }^{\mathrm{b}}$ Department of Materials and Mineral Resources Engineering, National Taipei Institute of Technology, \\ Taipei 10617, Taiwan, ROC \\ ${ }^{c}$ Department of Agricultural Engineering, National Taiwan University, Taipei 10617, Taiwan, ROC
}

Received 20 March 2000; received in revised form 24 November 2000; accepted 22 February 2001

\begin{abstract}
A revised fire outbreak and evacuation simulation model, MFIRE, is presented in the paper. The model provides information for setting up an emergency ventilation scheme, establishing safety procedures and minimizing damage in underground network systems. MFIRE simulates the interdependence between the ventilation system and its pertinent fans and structures, and the changes in ambient conditions and the heat source. A laboratory based fire simulation was conducted in a small physical tunnel network to verify the MFIRE. The rates of air flow and temperature distribution in each tunnel are compared with the simulated results obtained by MFIRE. Regarding air flow, the experimental rates correlate with the simulated results very well. Because of the reduced physical scale of the laboratory model, the simulated temperature distributions do not quite correlate with the laboratory data. MFIRE is employed to simulate a hypothetical fire outbreak in the Taipei Mass Rapid Transit System. The simulation is designed to investigate the direction and rate of air flow, temperature distribution and emergency ventilation responses. The results have confirmed that the proposed "pushpull" ventilation model can exhaust the high temperature air and smoke out of the underground facilities efficiently once the fire breaks out. (C) 2001 Elsevier Science Ltd. All rights reserved.
\end{abstract}

Keywords: Fire; Safety; Tunnel network; Ventilation

\section{Introduction}

On November 18, 1987, a major fire that started under an old escalator in London's King's Cross underground station killed 31 people and caused extensive

\footnotetext{
*Corresponding author. Tel.: + 886-2-2362-6480; fax: + 886-2-2363-9557.

E-mail address: lcw@gwater.agec.ntu.edu.tw (C.W. Liu).
} 


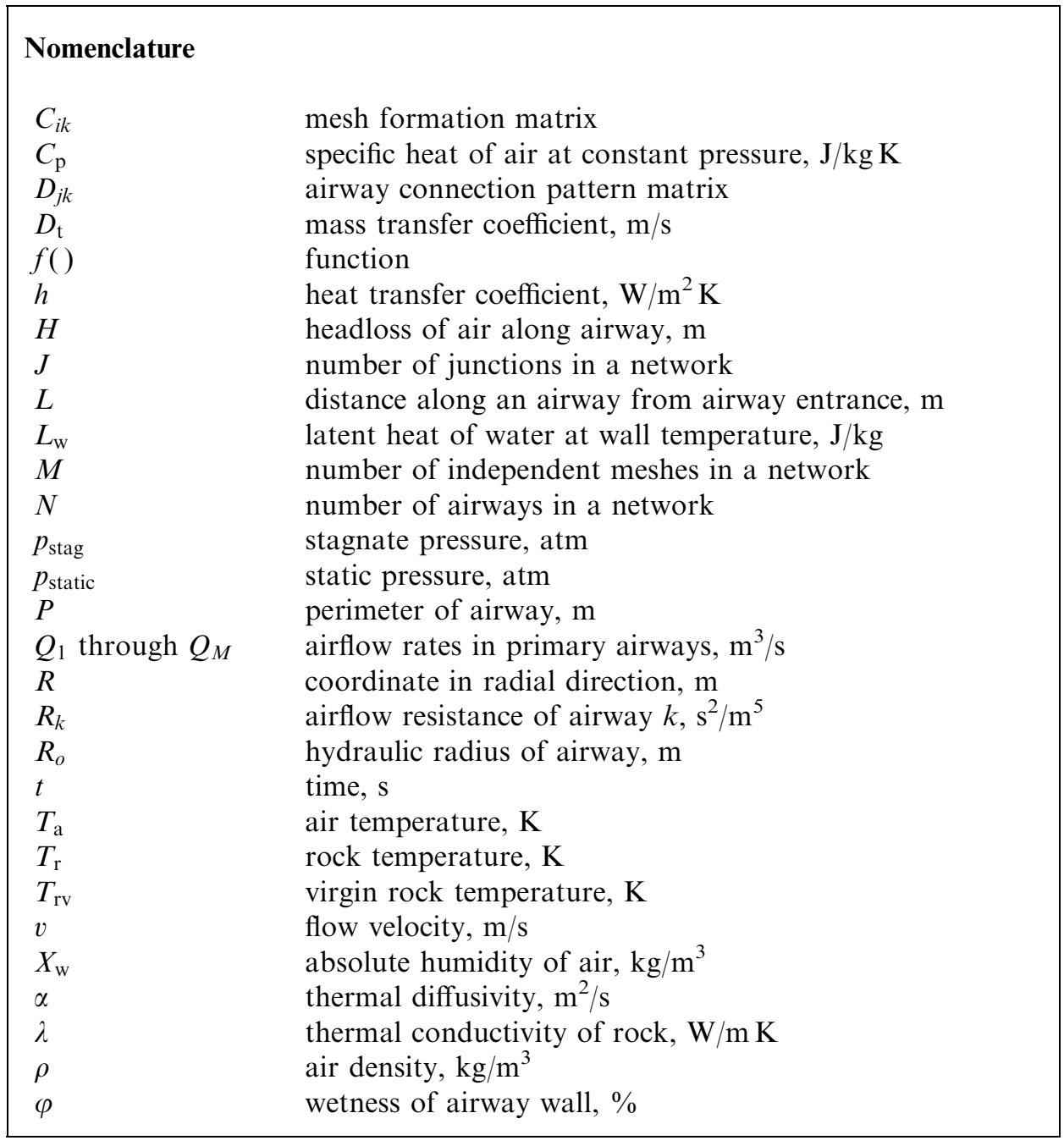

damages. The ensuing official inquiry laid blame on the management which led to a later reorganization [1]. The incident was attributed to the negligence and lack of clear fire-fighting procedures. In defending their case, London Underground official cited the fear of "needless disruption of services", since "fires occur several times a day somewhere in the Underground" [2].

Fires of the above kind have been known to occur from malfunctioning or overheated equipment, electrical short circuits, or negligence, to quite often by arson or sabotage. To illustrate the seriousness of the problem, the inquiry report attributed ten major fires in the underground in 1976 and 1985, to arson, theft or negligence. They caused 24 trains to be trapped in the affected areas and 2000 people suffered from injury or smoke inhalation. Turning to San Francisco, the Bay Area 
Rapid Transit (BART) system had experienced train fires in 1974, 1976, 1977, 1978, and 1979; most of them were related and confined to the car interior, but others arose from malfunctioning involving undercar equipment. Similar fire statistics are available from practically every subway system around the world.

Despite all the intended safety and vigilance precautions normally associated with the design, construction and operation of subway systems, fires have continued to occur throughout their development.

For most fire and safety officials, the prospect of employing ventilation to contend with a subway fire emergency goes against their instincts. It is known that airflow feeds oxygen to the fire and aids its growth. This would be true if the fire were oxygen starved as charcoal fires in barbecues. In a subway, however, the fuel is not as concentrated and except in enclosed spaces, the natural tunnel airflow provides enough oxygen to keep a subway fire fuel lean. Additional ventilation provided by fans helps control the fire by maintaining the airflow in a one-way direction and by bringing fresh, cool air to dilute the fire products of combustion.

Computer programs have been developed by using differential equations via finite difference methods to perform the considerable, and repetitive calculations required for tunnel ventilation studies. Most of the programs address the task of network analysis by conventional equations and formulas involving the geometry and construction particulars of a given system. In addition, certain programs take account of train motion and air flow induced by the action of train pistons. Yet others examine the environmental conditions, particularly at stations, and some have simulated a fire in progress and the related airflow pattern in specified time increments.

In a network that takes account of temperatures, the insensitive parameters of thermal conductivity, diffusivity and environmental factors, the hot air and smoke are controlled in specific tunnels. The simulated conditions and results can be utilized to define a safe evacuation route.

The objectives of this study are to establish fire ventilation simulator for the underground facilities in Taiwan, and to develop emergency ventilation systems and evacuation routes. The computer program MFIRE is adopted to address this issue.

A fire experiment conducted in the laboratory, involving a small physical tunnel network, was intended to verify the applicability of MFIRE. The air flow rate and temperature distribution in each tunnel were compared with the simulated MFIRE results. By modifying thermal conductivity, thermal diffusivity, environmental factors and the characteristic curve for the fan, MFIRE is then applied to simulating a fire outbreak in the Taipei Mass Rapid Transit system. The simulation results were analyzed and discussed to gain a further understanding of the emergency responses to underground fires.

\section{Literature review}

Underground mining has been permanently threatened by mine fires. Due to the existence of abundant combustible materials and difficult working conditions in 
mines, mine fires have more chances to start and less certainties of control. The US Bureau of Mines at the Pittsburgh Mining and Safety Research Center has been engaged in detailed experimental and theoretical studies concerning the nature of mine fires for many years. The Cape Breton Coal Research Laboratory has developed essential hardware and software and tested the methods of tracer-gas surveying techniques for ventilating mine gas. Mitchell and Burns [3] conducted case study of a mine fire. Braun [4] reviewed test methods and incident data for fires relating to portable electric cables in underground coal mines. The incident data indicated that the grouped configuration of cables on a reel accounted for a majority of the fires since 1970. Laage et al. [5] simulated the effects of mine-fire which has induced ventilation disturbances on the performance of a stench fire warning system. The study illustrates a technique for identifying the areas within a mine that are subject to unacceptable warning signal delays, thereby enabling preemptive action by mine personnel, such as redeployment of stench injectors. Wolski [6] presented a simplified method for evaluating the climatic conditions along a single underground mine airway, which was verified by a scale-down experiment. A real-time computer routine is described, which can be used as part of a fire simulation program to evaluate air temperature and humidities. Lea [7] used three computational models to study the effects of fire in an UK mine by employing one-dimensional gravity current techniques of measuring stratified flow up to breakdown. Multi-dimensional computational fluid dynamic modeling is used to examine the near-fire flow thoroughly. The model results are in agreement with each other and highlight a possible mitigation measure to limit the spread of combustion products. Recent advances in biotechnology to contend against fire hazard, water and air pollution in mines still have a long way to go. The progress so far is confined to material development only. Problem solving with classical physico-chemical techniques has virtually reached an impasse. Banerjee [8] has examined the scope and application of such bio-methods to the above-mentioned problems.

New subways and rapid transit and tunnels systems are in various stages of planning and construction throughout the world. Over the past 15 years, many advances have taken place in the system design. Changes have cast up many new problems for safety engineers: larger stations, larger numbers of people in transit, an increasing utilization of plastics in vehicle construction, and more electronically operated and controlled equipment. Burnett [9] reviewed the following complicated fire and safety issues: the combustibility and toxicity of transit car construction materials, emergency tunnel ventilation, tunnel emergency evacuation considerations, communications, breathing equipment and mobility. Anon [10] reported on methods of preventing transit system fires and outlined Metropolitan Atlanta Rapid Transit Authority's plans for preventing and fighting tunnel fires. In the design of the Atlanta subway system, steps were taken to ensure all facets of fire life safety: air handling, controls, water distribution and communications. Donato [11] studied the contribution of mechanical ventilation to fire safety in subways. Keski-Rahkonen et al. [12] conducted two full-scale pilot fire experiments in a tunnel. The first one was designed to simulate a fire in a subway car stalled in a tunnel. The second one simulated the case of a queue of cars which had caught fire 
in a tunnel. Baur [13] conducted a fire test in rail rapid transit cars. Miclea [14] developed a SES program which was used specifically to analyze subway ventilation systems. It can analyze the heat released into and extracted from a subway or vehicular tunnel, and determine the effects of the ventilation conditions on airflow throughout a network of stations and other merging tunnels. Current trends in legislation are aimed at imposing move stringent combustion testing of flexible foam products employed in domestic and contract furniture and mass transit seating. Large scale ignition tests, such as the California T.B. 133 in the USA, BS 5852 crib 5 in the UK and the AA standard in Japan, are considered to be the internationally accepted norm. Barker [15] developed a modified combustion system capable of meeting even the most stringent tests. In 1989, the design bureau of DPRM in Russia, the Metrovagonmash firm began to develop advanced subway cars, the 81720 and 81-721 models. Bykov [16] describes these cars briefly. In particular, it is pointed out that the body of each car is supported by two two-axis trolleys. The particular feature of the trolley is that there are only friction-free members, due to the use of rubbermetallic hinges.

\section{Numerical model MFIRE}

\subsection{Model description}

MFIRE was first developed by the Michigan Technological University (MTU) under the sponsorship of US Bureau of Mines. Its latest version is available (1.28) in PC software which was updated by MTU from an older, mainframe computer code [17].

The MFIRE program simulates the interdependence among a mine ventilation system, its pertinent fans and structures, and the changes in ambient conditions or a heat source, such as a fire. It also takes natural ventilation into consideration. The program is written in ANSI FORTRAN-77. The complexity of the network (500 airways) imposes no limits, except that blind-ended segments are not allowed. The MFIRE program comprises the following four parts [18]:

(1) Network calculation: The basic governing equations in a network problem can be derived by these theories: (1) the mass conservation law, (2) the constitutive equations, (3) the law of energy conservation. The ventilation network can be described by

$$
\begin{aligned}
& \sum_{k=1}^{N} D_{j k} Q_{k}=0 \quad(j=1,2, \ldots, J), \\
& H_{k}=R_{k}\left(\sum_{i=1}^{M} C_{i k} Q_{i}\right)^{2} \quad(k=1,2, \ldots, N), \\
& H_{i}=f_{i}\left(Q_{1}, Q_{2}, \ldots, Q_{M}\right)=0 \quad(i=1,2, \ldots, M),
\end{aligned}
$$


where $C_{i k}$ is the mesh formation matrix, $D_{j k}$ the airway connection pattern matrix, $f($ ) the function, $H$ the headloss of air along airway $(\mathrm{m}), J$ the number of junctions in a network, $M$ the number of independent meshes in a network, $N$ the number of airways in a network, $Q_{1}$ through $Q_{M}$ the airflow rates in primary airways $\left(\mathrm{m}^{3} / \mathrm{s}\right), R_{k}$ the airflow resistance of airway $k\left(\mathrm{~s}^{2} / \mathrm{m}^{5}\right)$.

Now, assuming a steady state in the system, MFIRE solves Eqs. (1)-(3) by the Hardy Cross method. The solutions can perform basic network balancing without considering heat/mass transfer, and predict the new pattern of updated airflow distribution.

(2) Temperature calculation: The air temperature at a given location behind a fire can be determined by the first law of thermodynamics

$$
Q \rho C_{\mathrm{p}} \frac{\mathrm{d} T_{\mathrm{a}}}{\mathrm{d} L}=\left.h P\left(T_{\mathrm{r}}-T_{\mathrm{a}}\right)\right|_{R=R_{0}},
$$

where $C_{p}$ is the specific heat of air at constant pressure $(\mathrm{J} / \mathrm{kg} \mathrm{K}), h$ the heat transfer coefficient $\left(\mathrm{W} / \mathrm{m}^{2} \mathrm{~K}\right), L$ the distance along an airway from airway entrance $(\mathrm{m}), P$ the perimeter of airway $(\mathrm{m}), R$ the coordinate in radial direction $(\mathrm{m}), R_{o}$ the hydraulic radius of airway $(\mathrm{m}), T_{\mathrm{a}}$ the air temperature $(\mathrm{K}), T_{\mathrm{r}}$ the rock temperature $(\mathrm{K}), \rho$ the air density $\left(\mathrm{kg} / \mathrm{m}^{3}\right)$.

The heat transfer model in the radial direction of airways considers the temperature of an air current along its source towards the surface, and heat and mass exchange between the air current and its surroundings. The heat transfer model is described below

$$
\frac{\partial T_{\mathrm{r}}}{\partial t}=\alpha\left(\frac{\partial^{2} T_{\mathrm{r}}}{\partial R^{2}}+\frac{1 \partial T_{\mathrm{r}}}{R \partial R}\right),
$$

subject to

$$
\begin{aligned}
& T_{\mathrm{r}}=T_{\mathrm{rv}} \quad \text { at } t=0 \text { for all } R, \\
& T_{\mathrm{r}}=T_{\mathrm{rv}} \quad \text { when } t>0 \text { and } R=R_{0}, \\
& \lambda \frac{\partial T_{\mathrm{r}}}{\partial R}=\phi T_{\mathrm{r}}+\varepsilon,
\end{aligned}
$$

where

$$
\begin{aligned}
& \phi_{i}=h+\varphi L_{\mathrm{w}} D_{\mathrm{t}} f^{\prime}\left(T_{\mathrm{w}, i-1}\right), \\
& \varepsilon_{i}=L_{\mathrm{w}} D_{\mathrm{t}}\left[\varphi f\left(T_{\mathrm{w}, i-1}\right)+\varphi f^{\prime}\left(T_{\mathrm{w}, i-1}\right) T_{\mathrm{w}, i-1}-X_{\mathrm{w}}\right]-h T_{\mathrm{a}}, \\
& T_{\mathrm{w}}=\left.T_{\mathrm{r}}\right|_{R=R_{0}},
\end{aligned}
$$

where $L_{\mathrm{w}}$ is the latent heat of water at wall temperature $(\mathrm{J} / \mathrm{kg}), D_{\mathrm{t}}$ the mass transfer coefficient (m/s), $t$ the time (s), $T_{\text {rv }}$ the virgin rock temperature $(\mathrm{K}), X_{\mathrm{w}}$ the absolute 
humidity of air $\left(\mathrm{kg} / \mathrm{m}^{3}\right), \alpha$ the thermal diffusivity $\left(\mathrm{m}^{2} / \mathrm{s}\right), \lambda$ the thermal conductivity of rock $(\mathrm{W} / \mathrm{m} \mathrm{K}), \varphi$ the wetness of airway wall $(\%)$.

The effects of heat transfer and mass diffusion were included in the governing equations, and the analytical solutions were pursed. Thermal states of air throughout a network system can be calculated and updated in an airway-by-airway process from a set of known initial conditions in the system.

(3) Transient-state simulation: Transient-state simulation which follows changes in ventilation step by step to offer a continuous snapshot of the ventilation pattern. The calculated results of the present time interval define the initial conditions for the next time increment so as to allow the procedure to be repeated in all successive time intervals and a series of pictures can be collated to illustrate the process of transient ventilation.

(4) Quasi-equilibrium simulation: Quasi-equilibrium simulation predicts the ventilation pattern in more or less steady state conditions after a relatively long period of time has elapsed.

The first part completes basic ventilation network calculations for a balanced airflow distribution in a ventilation system. The second part is equivalent to the steady-state ventilation simulation program, which provide a set of initial conditions for further simulation. The third part deals with the non-steady state ventilation simulation. It consists of a big DO-loop which stands for the number of time increment elapsed. At the beginning of each time increment, a check is made to see if a user-specified condition change should be activated. Then the initial conditions for the current time interval are set up. By far, the problem of simulation for a new time increment is defined.

If an airflow reversal happened in a system, some special concerns must be taken into account to assure an accurate simulation. As can be recalled, the data are updated in MFIRE in airway-by-airway, segment-by-segment processes. Airflow directions must be correctly indicated and data records for airways or control volumes must be stored in a predetermined order. When the airflow is reversed in an airway, data pertaining to the network must be reorganized to reflect the current airflow directions through mesh re-formation and airflow scheme array updating. The arrays related to air segments must also be rearranged to keep records in the correct order. Some other considerations may be necessary such as changed fan characteristics when an airflow reversal occurred in a fan branch.

Program MFIRE is a powerful and versatile tool in mine ventilation planning and fire control analyses. It can handle simulation of ventilation under dry and wet conditions based on the previously illustrated theoretical models for various processes. A user-specified time characteristics, to start a fire, change fire characteristics, stop a fire, change simulation steps, etc. during the process of a dynamic simulation. When it is properly used, a complicated situation can be simulated accurately with every detail being adequately described. Furthermore, a comprehensive data checking procedure in the program makes bug hunting in an input data file not difficult. All these features substantially improve MFIRE's usefulness, but make a concise presentation of the program's functions difficult. The above description serves only as an introduction to MFIRE. 


\subsection{Model setup and verification}

\subsubsection{Physical model setup}

A fire experiment was conducted on a small physical tunnel network in the laboratory to verify the applicability of MFIRE. A physical model was constructed with 316 stainless steel pipes, diameter $\oint=10.16 \mathrm{~cm}$, with 15 nodes and 27 tunnels, each $1.9 \mathrm{~m}$ long $\times 1.25 \mathrm{~m}$ wide. The schematics of the physical model are illustrated in Fig. 1. The schematic of a network of the physical model for both experimental and numerical simulations is displayed in Fig. 2. A heater of $1 \mathrm{~kW}$ was located at node 501 as a fire source. An axial fan was positioned in tunnel 302 to push air from outside the network through both a converging nozzle and a comb rectifier box into the network.

Measuring the static and stagnation pressure at some location in the flow can provide the rate of velocity there. The differential pressure between the static and stagnation pressures was measured both by a differential pressure transducer and a pitot tube. Applying the Bernoulli equation between the tip and side holes of the

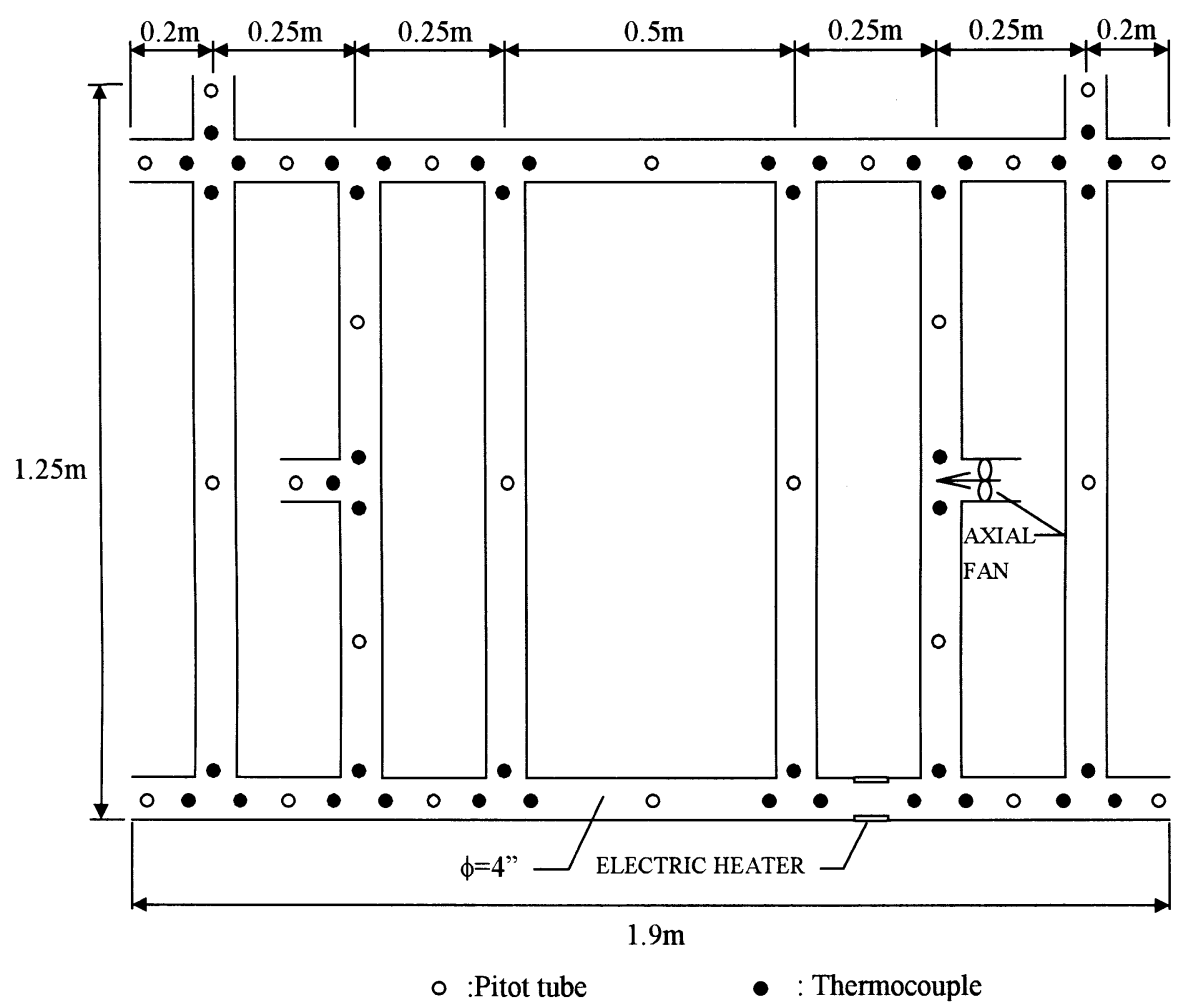

Fig. 1. Schematic of the physical model. 


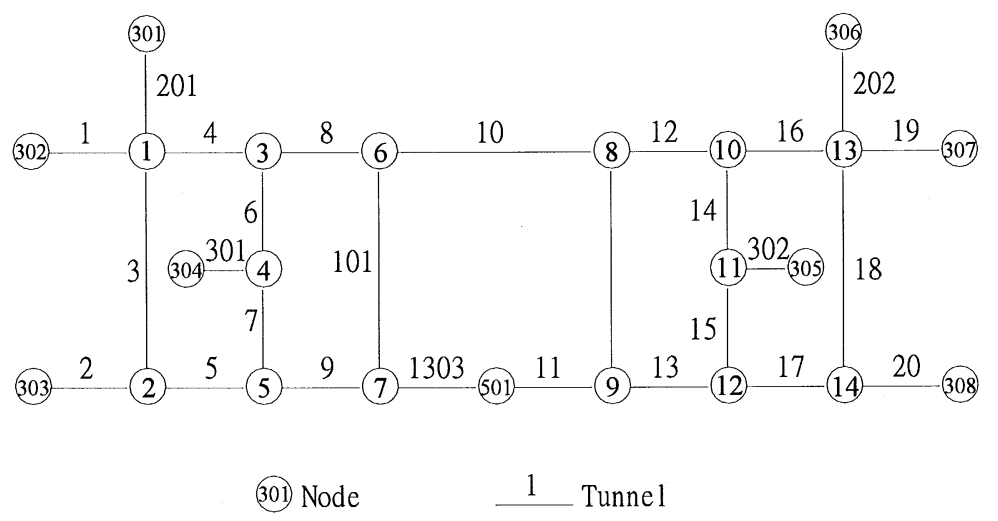

Fig. 2. Schematic of network of the small physical model for both experiment and numerical simulation.

probe, assuming a steady incompressible flow, gives

$$
p_{\text {static }}+\frac{1}{2} \rho v^{2}=p_{\text {stag }},
$$

where $p_{\text {static }}$ is the static pressure (atm), $p_{\text {stag }}$ the stagnation pressure (atm), $v$ the flow velocity $(\mathrm{m} / \mathrm{s})$.

Solving for the flow velocity, yields

$$
v=\sqrt{\frac{2}{\rho}\left(p_{\text {stag }}-p_{\text {static }}\right)} .
$$

The average temperature and pressure measured $23.3^{\circ} \mathrm{C}$ and $1 \mathrm{~atm}$, respectively, in the laboratory during the experiment. Air density can be calculated from the perfectgas law as $1.178 \mathrm{~kg} / \mathrm{m}^{3}$. Therefore, the velocity becomes

$$
v=414.8 \sqrt{p_{\text {stag }}-p_{\text {static }}} \text {. }
$$

The temperature was measured by a K-type thermocouple. The thermocouple was inserted so that the junction is located at the center of the pipe in which temperature measurement is desired. When measuring gases at high temperatures, the cooling of the junction by radiation to the surrounding cool walls is frequently significant. A radiation shield around the thermocouple allows the latter to observe a surface of a temperature only slightly lower than that of the gas in which it is immersed [19]. Fig. 3 illustrates the construction of the thermocouple junction with the pressed radiation shield. The thermocouple was calibrated by direct calibration. Fig. 4 displays the flowchart of data measurement and communication. MFIRE simulates the experimental fire case for the same laboratory physical network.

\subsubsection{Model verification}

When the fire experiment took place in the small-scale physical tunnel network, the electrical heater was located at node 501, and the ventilating fan in tunnel 302. The fan's flow rate was $8.5 \mathrm{~m}^{3} / \mathrm{min}$, but no ventilation was performed during the fire. 


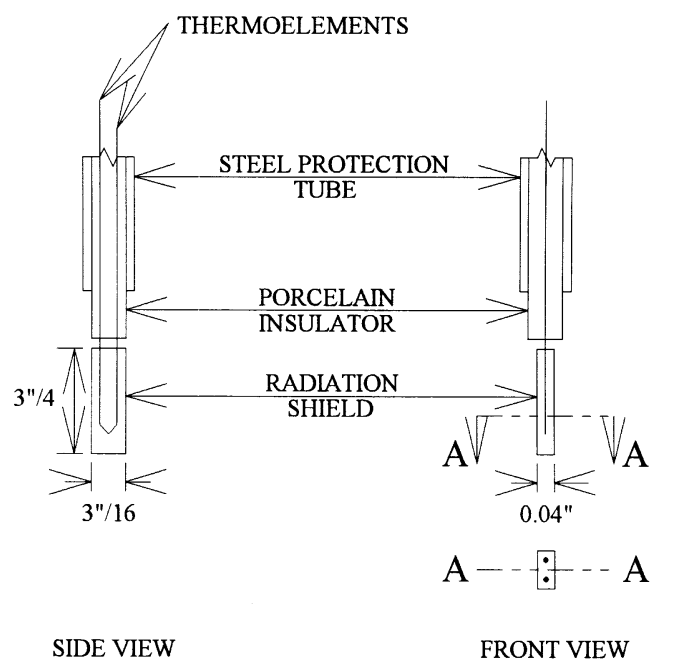

Fig. 3. The construction of a thermocouple junction with a pressed radiation shield.

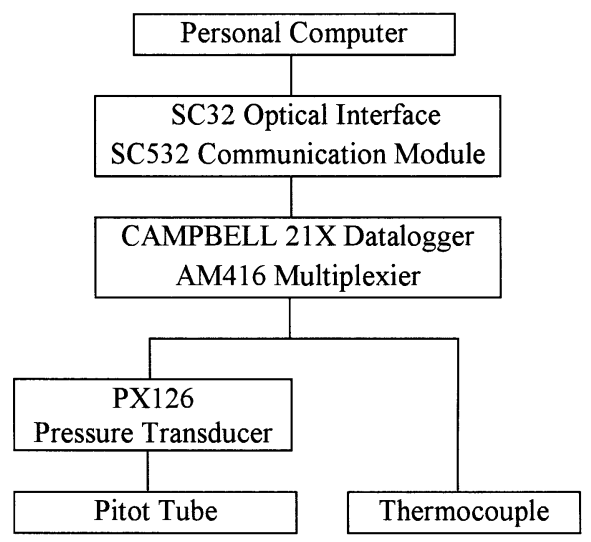

Fig. 4. The flowchart of data measurement and communication.

For both the numerical simulation and the physical experimental results, the heat produced by the fire could not be quickly discharged from the network system, and it, therefore built up in the fire tunnel. This caused the gas temperature in the tunnel to rise to $500^{\circ} \mathrm{C}$ within $20 \mathrm{~min}$, thus creating a high temperature environment. At this stage the hot gas gradually expanded into the downstream part of the tunnel, causing the temperature there to rise slowly. If at this juncture the fan was activated to provide ventilation, the hot gases rapidly discharged and the tunnel temperature gradually dropped to an equilibrium of approximately $55^{\circ} \mathrm{C}$.

Tunnel 11 was selected as the escape route, and the escape direction was from node 501 to node 9; the direction of ventilation in this tunnel was from node 9 to node 7 . When ventilation was begun immediately after the outbreak of the fire, the 
experimental temperatures at 10, 180, and 1800 s were listed in Fig. 5. Figs. 6(a) and (b) illustrate the temperature changes and their elapse times in the different tunnels, according to the experimental measurements and to MFIRE simulations. The results reveal that when hot gases pass through a tunnel, both experimental and simulation results indicate that the situation became stable after an equilibrium temperature is
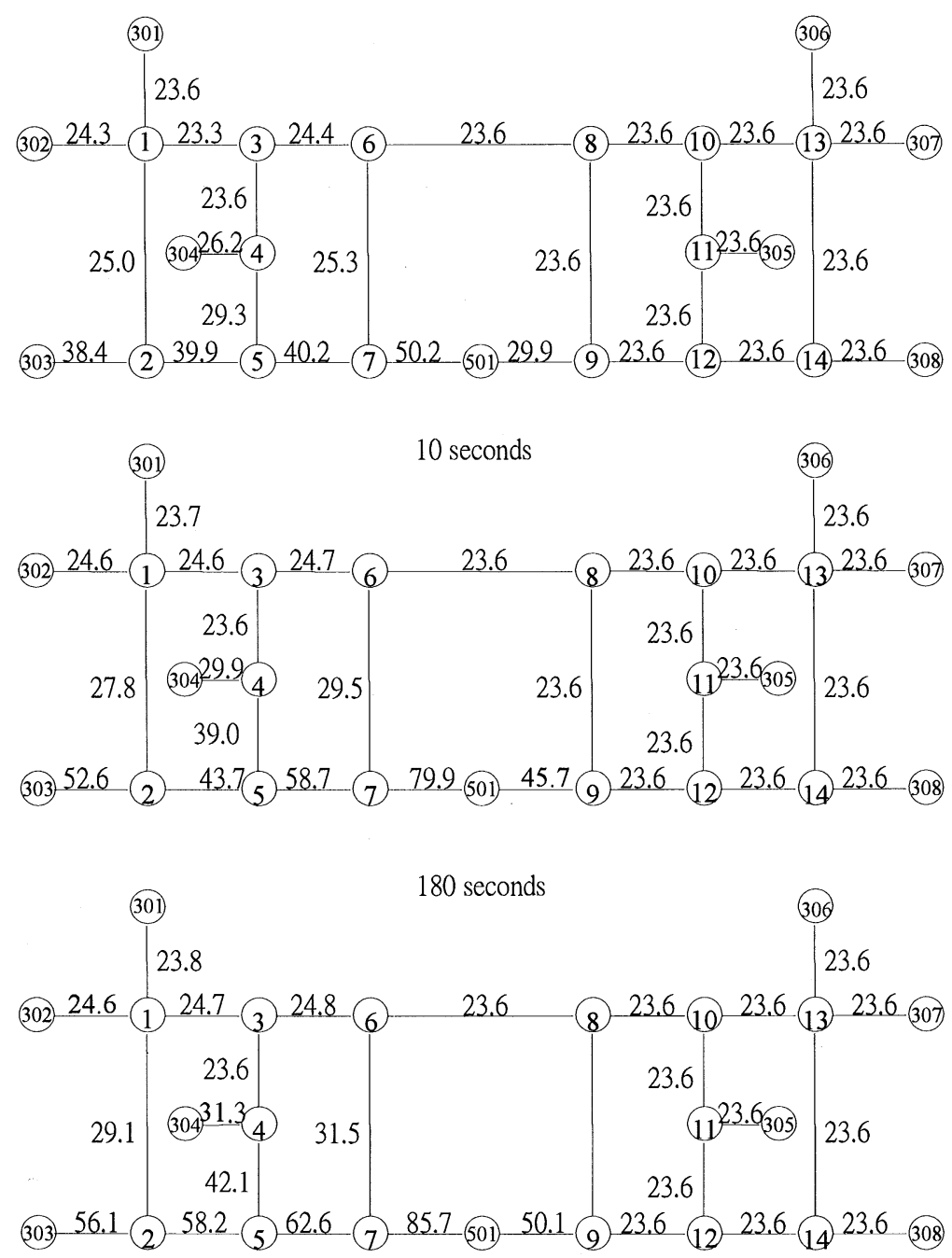

1800 seconds

(301) Node $\quad 23.6$ The average temperature in tunnel.(unit $={ }^{\circ} \mathrm{C}$ )

Fig. 5. The experiment results of temperature for 10,180 , and $1800 \mathrm{~s}$ for the physical model. 

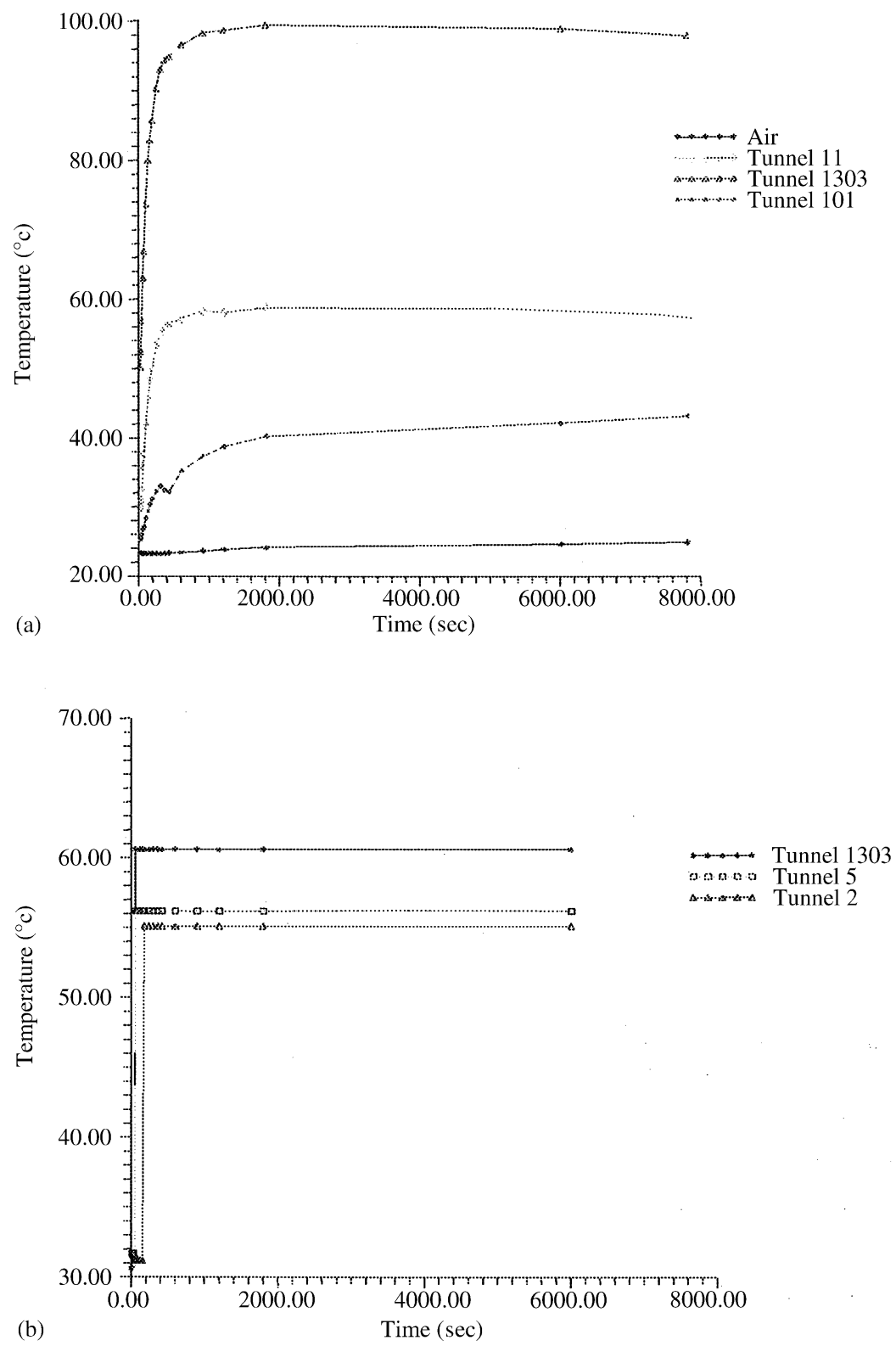

Fig. 6. (a) The changes with time of temperatures in atmosphere and tunnel 11, 1303, and 101 according to experimental measurement for the physical mode. (b) The changes with time of temperatures and tunnel 1303, 5, and 2 according to MFIRE simulation for the physical model. 
reached, and the temperature ceases to rise continuously. However, as far as the time needed to reach a stable temperature is concerned, the results of the numerical simulation indicate that the stable condition reaches sooner than that in the actual experiment. Fig. 7 illustrates the simulated temperature distribution in the tunnel network for $10,60,180$, and $1800 \mathrm{~s}$ for the physical model. Figs. 5-7 also illustrate the simulated temperature distribution do not correlate well with laboratory data. The difference is perhaps caused by the limited physical scale of laboratory model.

Fig. 8 illustrates a comparison of MFIRE and experiment simulation results for ventilation in the physical model. The square of correlation coefficient, $r^{2}$, an important measure of the relationship between two variables in statistics, was used to measure how strongly related for the two sets of MFIRE and experiment simulation results. The calculated value of $r^{2}=0.97$ can be approximated by unity. The value of $r^{2}$ near 1 implies that large flowrate of MFIRE simulation result tend to occur with large flowrate of experiment result, and vice versa, small flowrate of MFIRE simulation result with small flowrate of experiment result. It is evident from Fig. 8 and value of $r^{2}$ that the two sets of simulation result data were largely identical. The figures reveal a relatively large difference between these tunnels which were located in the vicinity of the fan outlet, but only a relatively small difference between the other tunnels. The differences perhaps arise because the numerical model did not take account of the wind resistance caused by the electric heater or of the fact that pressure drop losses may change due to the different angles of the tunnel junctions. The latter effect may largely explain the differences between these tunnels which were located in the vicinity of the fan outlet. Other discrepancies in experimental measurements may have been due to the instability in the fan's operation.

\section{Model application}

\subsection{Taipei mass rapid transit system}

The selected sector of the Taipei Mass Rapid Transit (TMRT) network system for the field site simulation lies between stations BL14 and BL17 on the BLUELINE. The system layout is depicted in Fig. 9. The tunnels have a circular area of $21 \mathrm{~m}^{2}$ with concrete sets for support and relatively rough walls. Generally, the tunnels are graded upwards toward the stations, to minimize braking effort and station below ground level depth. The two trackways run through separate tunnels between stations, but share a twin-track tunnel in stations, having a cross sectional area of $134 \mathrm{~m}^{2}$. Ventilation shafts are positioned in tunnels $213,214,300,301$, 302, 305 and 308, all in the vicinity of each end of the station. These shafts function as pressure (or draught) relief shafts for train-induced airflow but are also equipped with fans that can be activated in case of emergency, such as a tunnel fire. The shafts in this model are circular shaped, with a cross sectional area of $10 \mathrm{~m}^{2}$. 

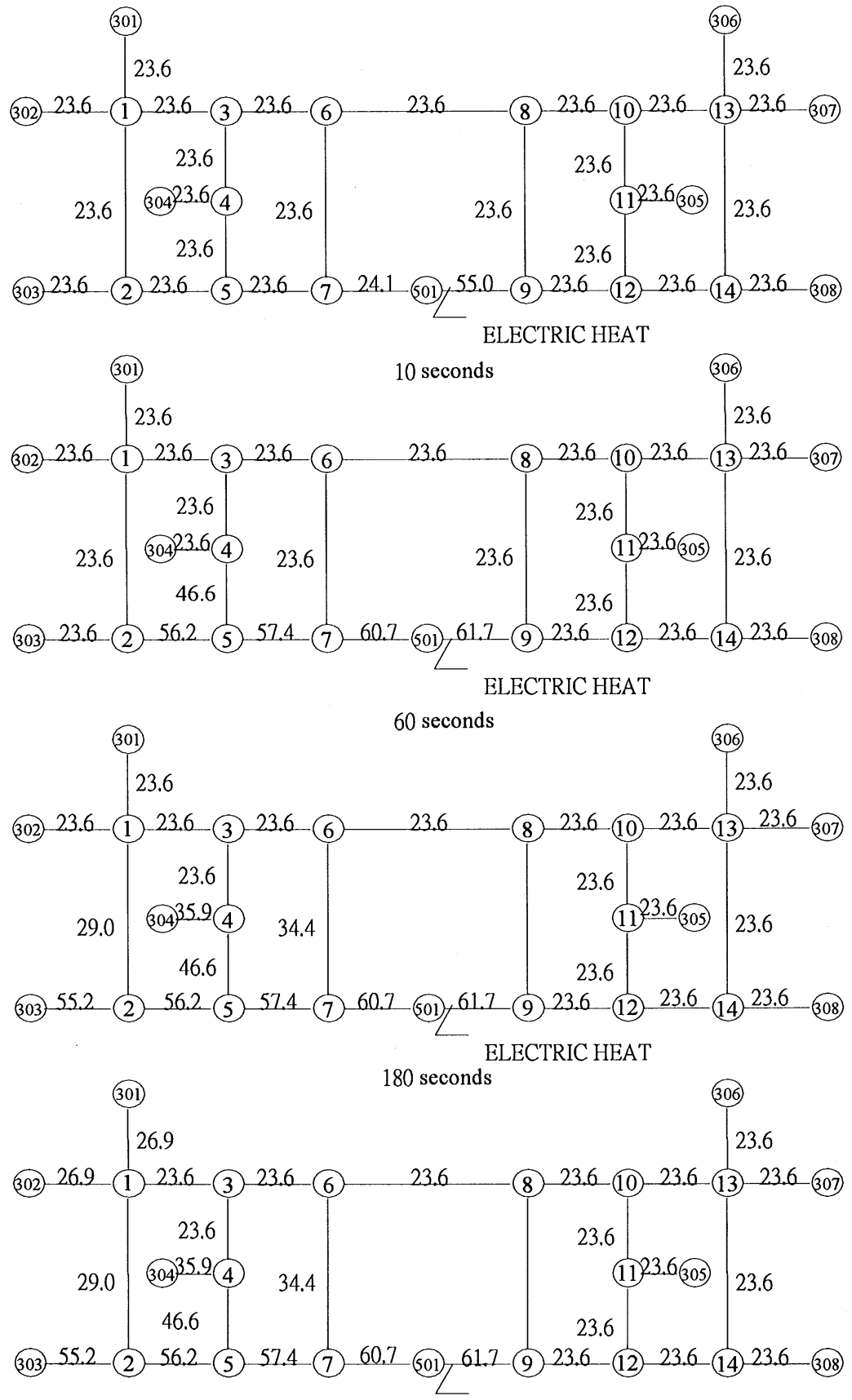

1800 seconds

(301) Node 23.6 The average temperature in tunnel unit $={ }^{\circ} \mathrm{C}$

Fig. 7. The MFIRE result of temperature for $10,60,180$, and $1800 \mathrm{~s}$ for the physical model. 


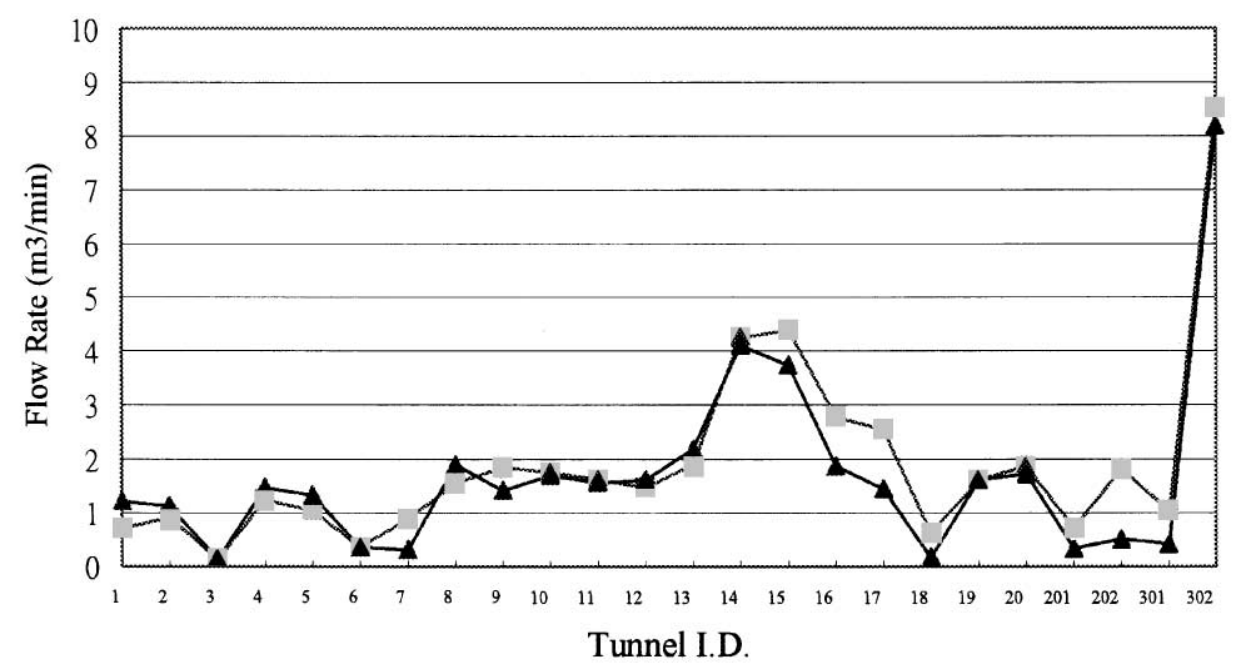

(a)

\section{The MFIRE Result \-The Experiment Result}

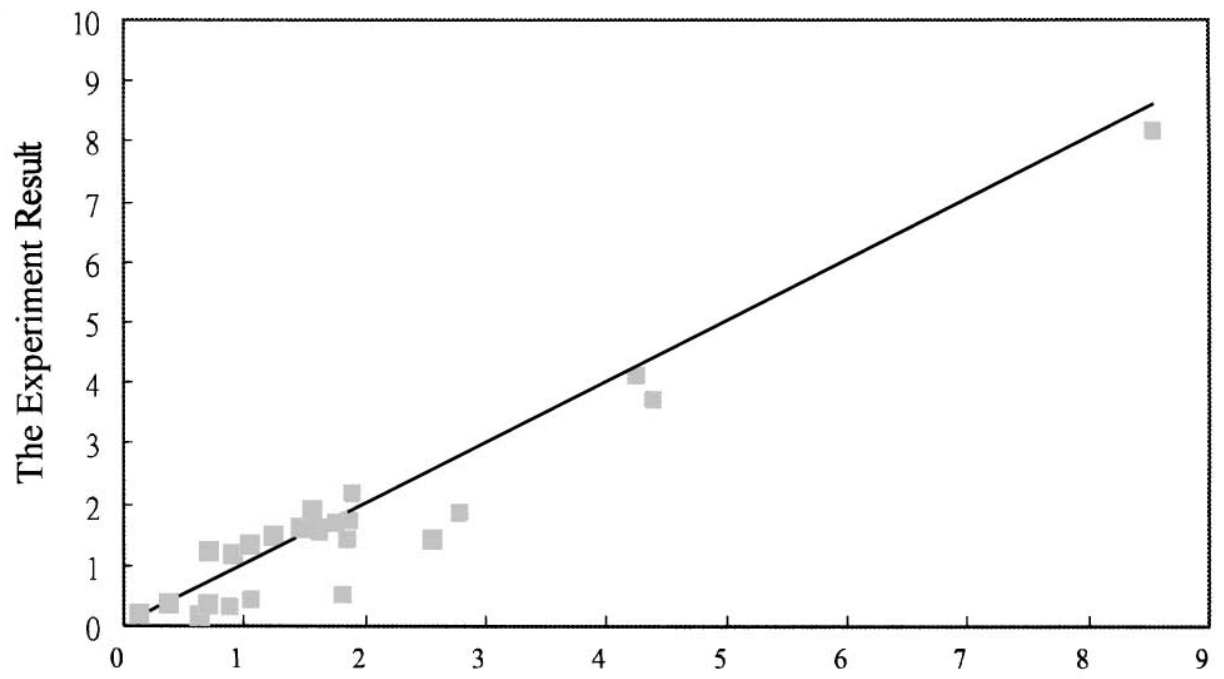

(b)

The MFIRE Result

Fig. 8. The comparison of MFIRE and experiment result of ventilation flow rate for the physical model $\left(r^{2}=0.94\right)$.

The station comprises two levels, lower platform level and an upper level for ticketing and screening the passengers, with a cross sectional area of 82 and $54 \mathrm{~m}^{2}$, respectively. From the upper level, two entrances given on the street level either by stairways or/and escalators. The cross sectional area of each entrance is $15 \mathrm{~m}^{2}$. 

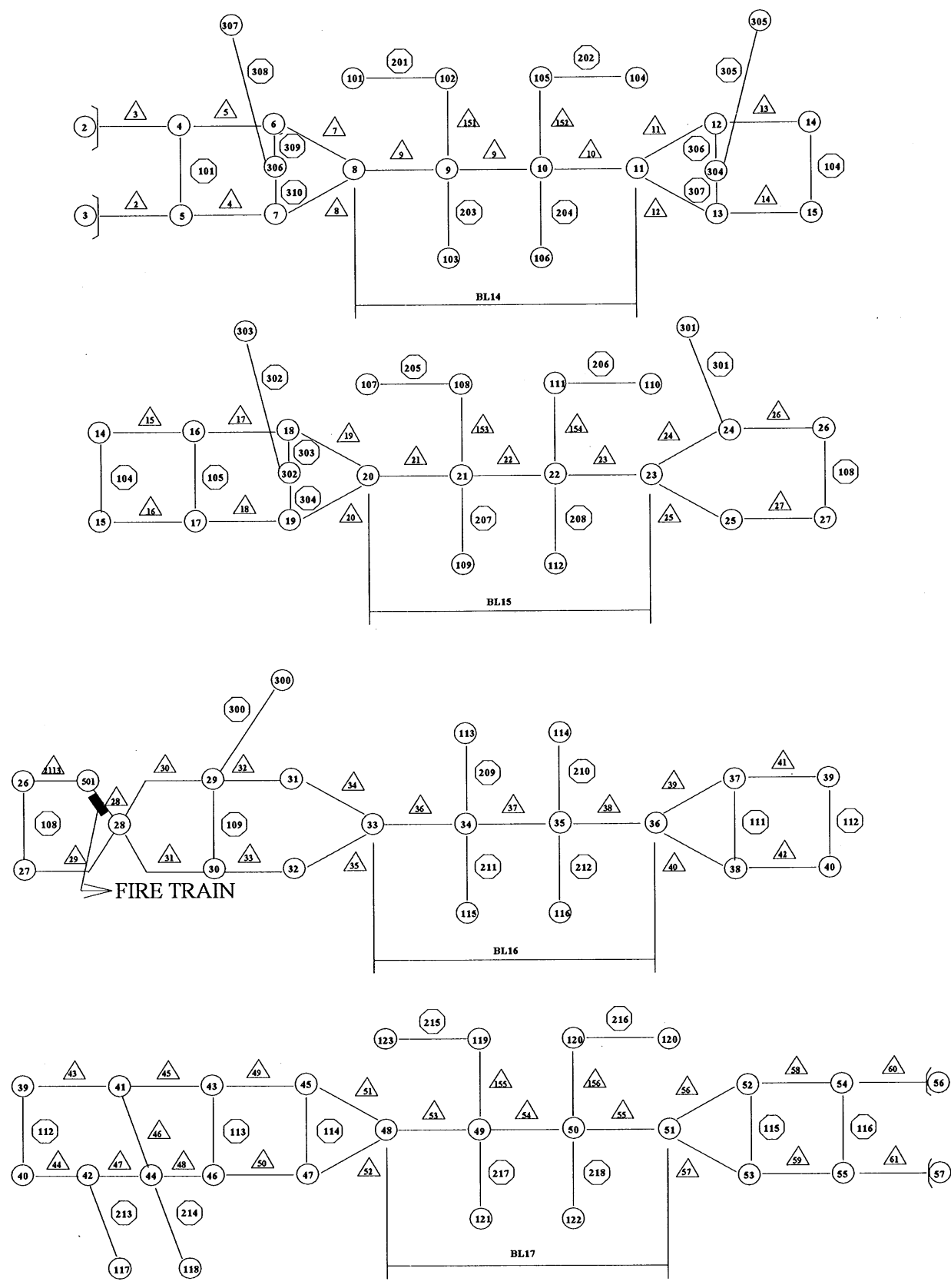
(33) Node
(11is) Ventilation Tunnel
139. Train Tunnel

Fig. 9. The field site simulation network. (The network system from station BL14 to BL17 in BLUELINE of TMRT system.) 
Single, reversible axial fans that can move $65 \mathrm{~m}^{3} / \mathrm{s}$ of air at $1679 \mathrm{~Pa}$ pressure are employed in the shafts between BL15 and BL16 for "push-pull" ventilation model. A fire of $337 \mathrm{~kW}$ sensible heat was simulated at node 501 .

The thermal conductivity, thermal diffusivity, environmental factor and fan characteristic curves are modified before MFIRE is employed to simulate a hypothetical fire outbreak in the TMRT system. The simulation is designed to determine whether the current "push-pull" ventilation model can efficiently exhaust the high temperature air and smoke out of the underground facilities. The "push-pull" ventilation model is displayed in Fig. 10.

The MFIRE employs a trial-and-error approach to estimate the emergency ventilation system. The interactions are between the tunnel air velocity (past the fire site) as predicted by the MFIRE and a designed air velocity criterion which precludes the possibility of smoke backing against the ventilating air stream ("backlayering"). A typical application of the fire model consists of the following steps:

- Perform MFIRE simulation to determine tunnel air velocity and hot air temperature.

- Determine the required air velocity.

- If the predicted air velocity exceeds the required air velocity, the ventilation system is considered adequate.

- If the predicted air is less than the criterion, change the system.

\subsection{Simulation results and discussion}

MFIRE is used to model a hypothetical fire outbreak in the TMRT system. As a train travels along tunnel 28 to station BL15, a fire of $337 \mathrm{~kW}$ occurs at node 501 . Immediately following, conducting the "push-pull" ventilation in the fire tunnel and stops other trains and activates the network's fan operation system. Tunnel 28 was the selected escape route and the escape direction was from node 2113 to node 28 .

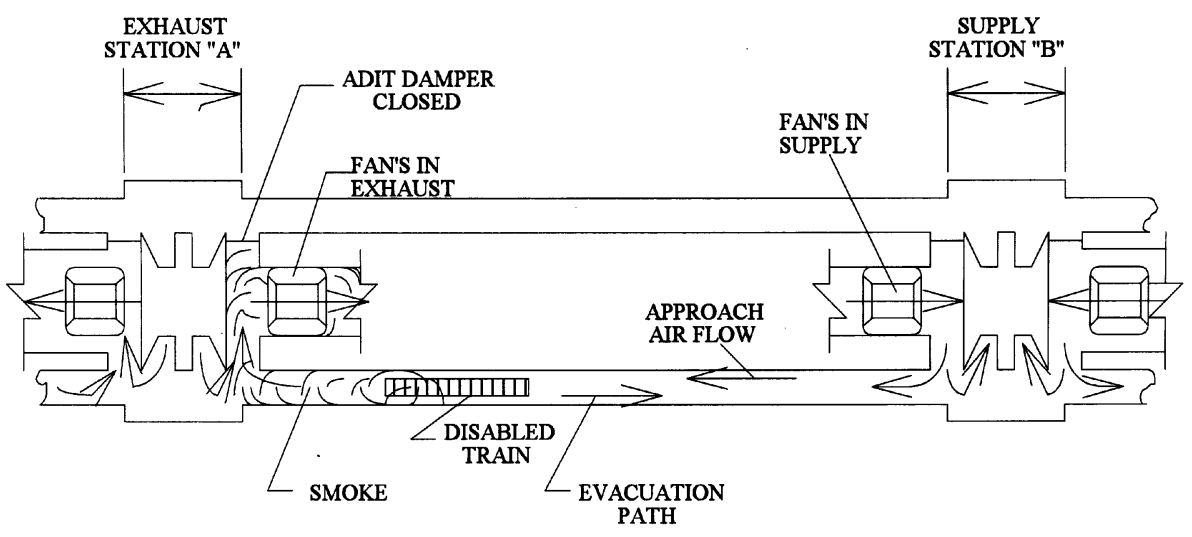

Fig. 10. Tunnel fire emergency using "push-pull” ventilation model. 

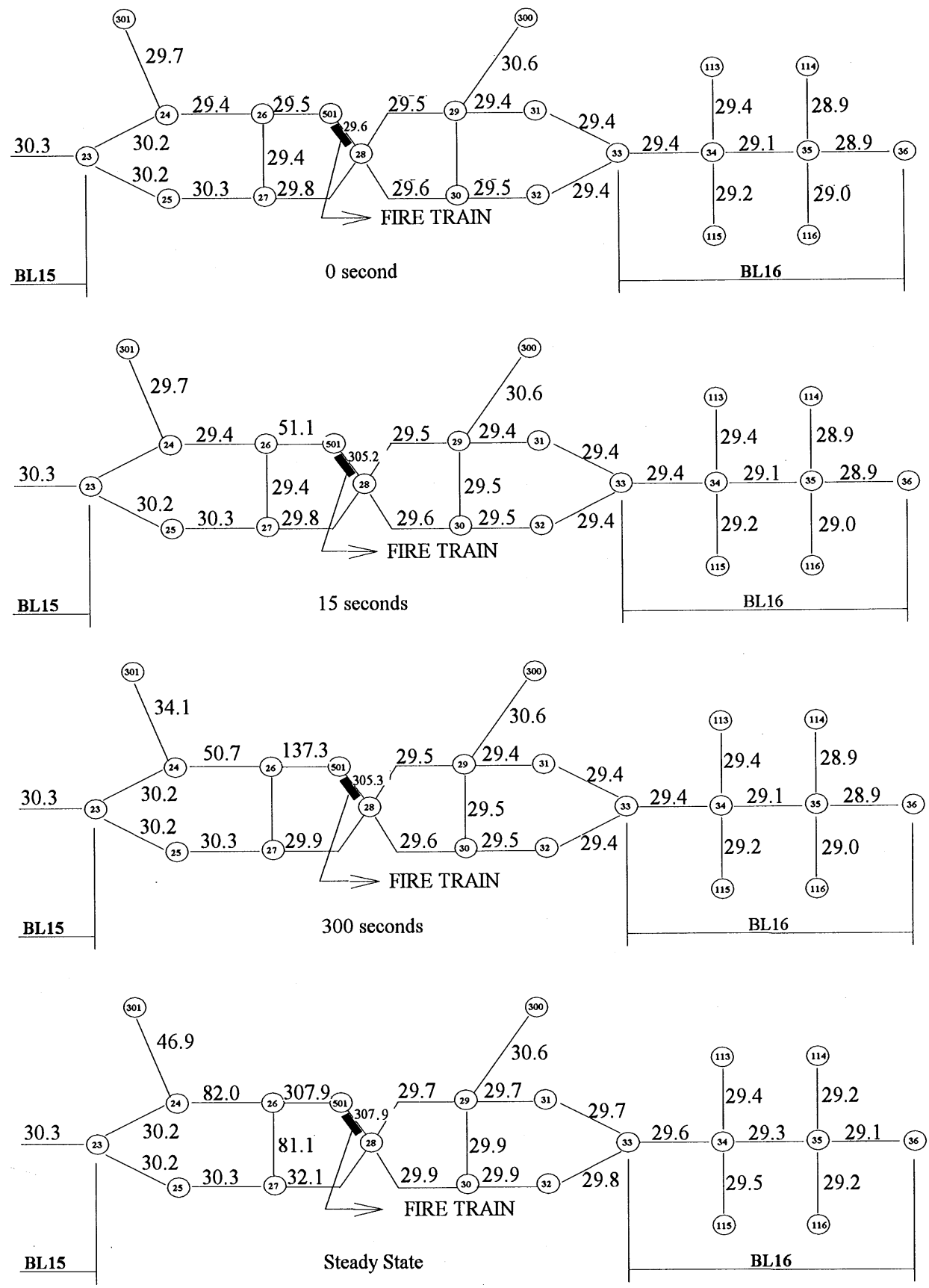

(3) Node $\quad 30.3$ The average temperature in tunnel.(unit $={ }^{\circ} \mathrm{C}$

Fig. 11. The MFIRE result of temperature for these tunnels in the vicinity of the fire tunnel (tunnel 2113) for $0,15,300$, and steady-state for the TMRT system. 

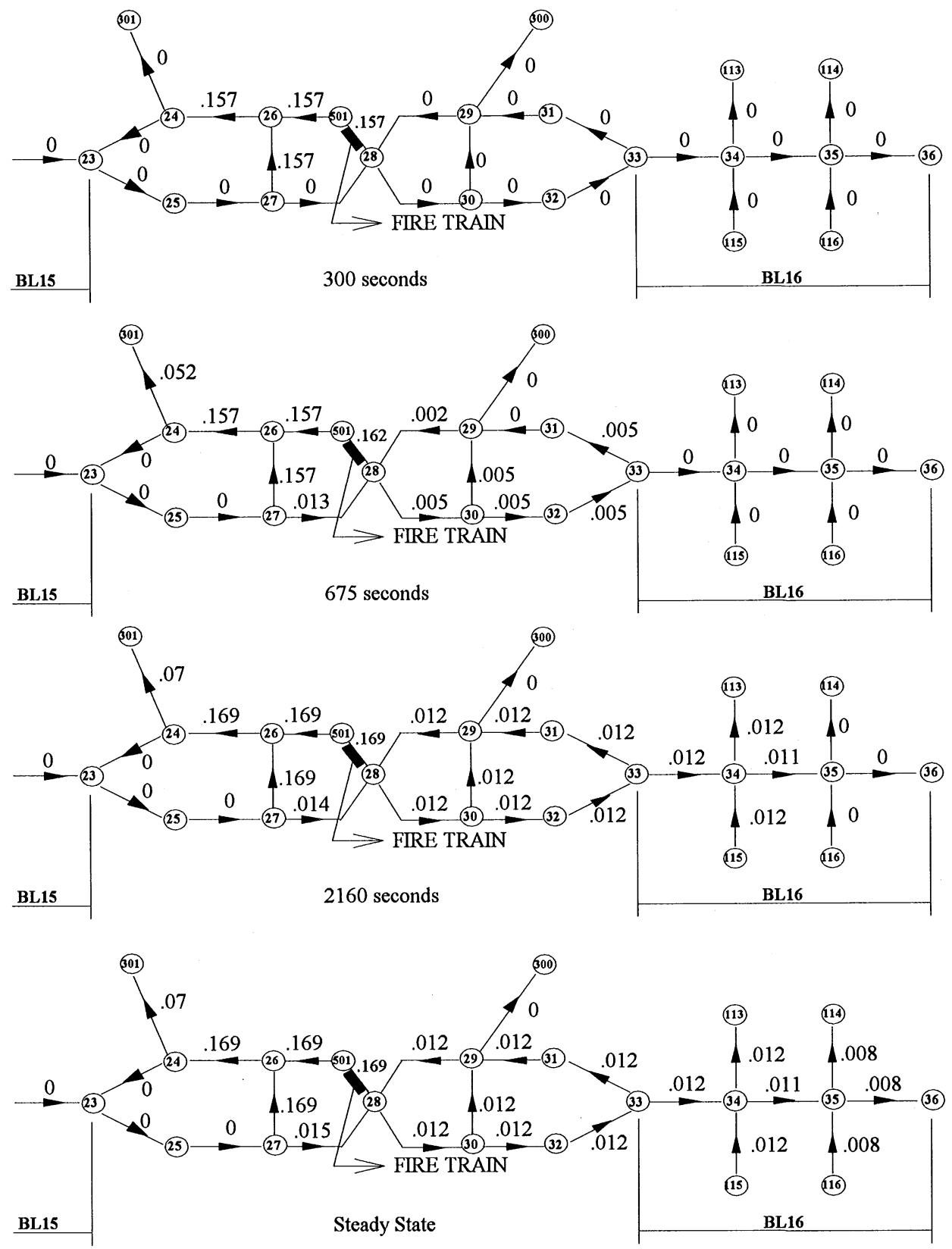

(53) Node $\quad .008$ The average concentration and direction of smoke in tunnel.(unit $=\%$ )

Fig. 12. The MFIRE result of smoke concentration in the vicinity of the fire tunnel (tunnel 2113) for 300, 675,2160 , and steady-state for the TMRT system. 
The direction of ventilation in this tunnel was from node 28 to node 26 . A minimum air velocity of $1.5 \mathrm{~m} / \mathrm{s}$ is required to control the "backlayering". The air velocity anywhere along an evacuation route should not exceed $11 \mathrm{~m} / \mathrm{s}$ because some people may experience difficulty in walking against velocities higher than that and thus hindering the evacuation. This program was run on an IBM 80486 Personal Computer with a clock speed of $220 \mathrm{MHz}$. The CPU time for MFIRE was 4 min $18 \mathrm{~s}$. The airflow simulation results also confirmed that the thermal effects of fire induced the change of flow rate in each tunnels immediately reaches a stable state. The flow rate of tunnel 28 is maintained at $3683 \mathrm{~m}^{3} / \mathrm{min}$ and the air velocity at $3 \mathrm{~m} / \mathrm{s}$ during fire is adequate for safe evacuation. The temperature simulation results for other tunnels in the vicinity of the fire tunnels $0,15,300$, with the steady-state are given as in Fig. 11. The results indicate that the temperature of the fire tunnel, tunnel 28, rises immediately to almost the highest temperature $290^{\circ} \mathrm{C}$. Simultaneously, the hot gas gradually expands into the downstream part of those tunnels with "push-pull" ventilation model and causes the temperature there to rise slowly. The other tunnels without "push-pull" ventilation system almost maintain normal temperature. The smoke concentration distribution in the vicinity of the fire tunnels $300,675,2160$,
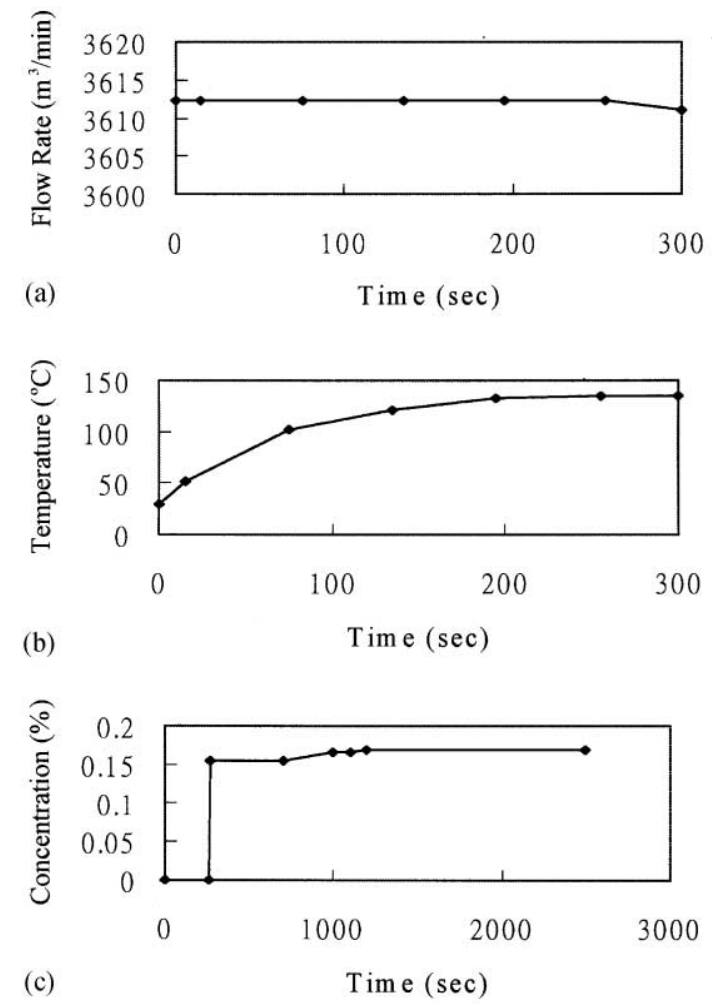

Fig. 13. The change with time in the fire tunnel (tunnel 2113) of (a) airflow rate, (b) temperature, (c) smoke concentration. 
with the steady-state are listed in Fig. 12. Some smoke can flow into station BL16. A comparison of Figs. 11 and 12 indicates that heat transfer occurs faster than smoke travels. Figs. 13(a)-(c) illustrates the change of airflow rate, temperature and smoke concentration with time in the fire tunnel, respectively. The curves here are smooth and differ from Miclea's simulation [20], which exhibits a zigzag variation.

The results show that the simulated high temperature tunnel and the smoke path did not change due to changes of thermal conductivity, diffusivity and environmental factors. The high temperature tunnel exists only when massive amounts of hot air flow through it.

\section{Conclusions}

A MFIRE numerical model was presented to simulate fires in underground facilities in Taiwan. The functions of this model include providing data essential for installing emergency ventilation systems, analyzing the strengths and shortcomings of various types of emergency ventilation methods, determining the most effective ventilation method, and selecting appropriate escape routes to minimize injury to people and property.

Physical experiments of fire and ventilation were conducted in the study. In order to verify the applicability of the MFIRE, a ventilation system was employed and air flow and temperature distributions within the various tunnels of the designed system was measured.

Both the numerical simulation and the physical experimental results indicated that the heat produced by a fire without ventilation could not discharge from the system quickly, thus creating a high temperature environment. However, if a fan was activated timely to provide ventilation, the hot gases could quickly discharge and the tunnel temperature fell to an equilibrium value gradually. If mechanical ventilation was applied immediately after the outbreak of fire, both the experimental and simulation results had indicated that stability could be achieved once an equilibrium temperature was reached, and the temperature stopped to rising. However, the simulated temperature distribution does not correlate with the laboratory data very well because of the reduced physical scale of the laboratory model.

The air flows in the ventilation system obtained through both the experimental and the numerical simulations, in contrast to temperature simulation, were practically coincident.

MFIRE simulated a hypothetical fire incident in the TMRT system. The simulation results of airflow confirmed that the flow rate of fire and evacuation tunnel is adequate for the safe evacuation of people. On the other hand, the simulation results of temperature showed that the temperature of the fire node rises immediately to near the highest temperature. At the same time, the hot gas in the "push-pull" ventilation model gradually expands into the downstream part of the tunnel where the temperature rises slowly. On the contrary, the other tunnels without "push-pull" ventilation model maintain almost normal temperature. The current 
"push-pull" ventilation method can extract the high temperature air and smoke out of the underground facilities efficiently.

\section{Acknowledgements}

The authors would like to thank the National Science Council of ROC for partially financing this research under contract NSC82-0410-E-027-021, NSC830410-E-027-001, and NSC84-2211-E-027-002. The authors also thank Dr. KuoLiang Pan of Water Resources Bureau of ROC for his thorough review and editing of the manuscript. Gratitude is also due to Professor Y.J. Wang of West Virginia University who kindly directed our interest in this subject and offered suggestions during the course of work.

\section{References}

[1] Fennell D. The king's cross investigation-executive summary to the transport secretary by the inspector. Modern Railway 1988;45(483):619-20.

[2] Hope R. Trench effect that killed 31-special report on the king's cross fire. Railw Gaz Int 1989;145(1):29-33.

[3] Mitchell DW, Burns FA. Interpreting the state of a mine fire. US Dept of Labor, Mine Safe and Health Adm., Washington, DC, USA: Goverment Printing Office, 1979.

[4] Braun E. Review of fire test methods and incident data for portable electric cables in underground coal mines. National Bureau of Standards, NBSIR 81-2292, National Engineering Lab Corp, Washington, DC, USA, 1981.

[5] Laage L, Pomroy W, Weber T. Computer modeling of the effect of mine-fire-induced ventilation disturbances on stench fire warning system performance. Bureau of Mines, BUMINESIC-9154, Twin Cities Research Center, Minneapolis, MN, USA, 1987.

[6] Wolski JK. Method for predicting airway climatic conditions during a fire and its validation using reduced scale experiments. Min Sci Technol 1991;12(3):299-310.

[7] Lea CJ. Computational Modeling of mine fires. Min Eng (London) 1994;154(394):17-21.

[8] Banerjee SC. Scope of application of bio-technology for fire-control and ameliorating environmental pollution of coal mines. J Mines Met Fuels 1995;43(1-2):17-21.

[9] Burnett J. Fire safety concerns for rail rapid transit systems. Fire Safety J 1984;8(1):3-7.

[10] Anon. Fire life safety the subway. ASHRAE Journal 1984;26(4):36-40.

[11] Donato G. Contribution of mechanical ventilation to fire safety in subways. International Symposium on the Aerodynamics and Ventilation of Vehicle Tunnels 5th (LILLIE) 1985. pp. 31-49.

[12] Keski-Rahkonen O, Holmlund C, Loikkanen P, Ludvigsen H, Mikkola E. Two full scale pilot fire experiments in a tunnel. Valtion Teknillinen Tutkimuskeskus, VTT/RR-453, Palotekniikan Lab, Espoo, Finland, 1986.

[13] Baur L, Cabos H, Haumann D. Fire tests in rail rapid transit cars. German: Verkehr Und Technik, 1989. pp. 93-94.

[14] Miclea PC. Application of SES and MFIRE computer simulation programs for tunnel fire modeling — a comparative study. Oakland, CA, USA: ICF Kaiser Engineers Inc., 1991.

[15] Barker M. Combustion modified moulded polyurethane flexible foam for the furniture industry. Cell Polym 1992;11(2):83-95.

[16] Bykov EM. Advanced subway cars of the 81-720 and 81-721 models. Tyazh Mashinostr 1995;4:8-10. 
[17] Chang XT, Laage LW, Greuer RE. A user's manual for MFIRE: a computer simulation program for mine ventilation and fire modeling. US Bureau of Mines Information Circular, No. I 28.27:9245, 1990.

[18] Chang XT. The transient-state simulation of mine ventilation systems. Ph d Disseration at Michigan Technological University, USA, 1983.

[19] Considine DM. Process instruments and controls handbook, 2nd ed.. New York, USA: McGrawHill, Inc., 1974.

[20] Miclea PC, Murphy RE. Assessment of emergency ventilation capability in case of train fire in a tunnel using "subway environment simulation" (SES) computer program. Proceedings of 4th US Mine Ventilation Symposium 1989. 